RGSA - Revista de Gestão Social e Ambiental

Jan. - Abr. 2009, V.3, No.1, p. 70-86

www.rgsa.com.br

\title{
SUSTENTABILIDADE EMPRESARIAL E VALOR DAS AÇÕES: UMA ANÁLISE NA BOLSA DE VALORES DE SÃO PAULO
}

\author{
Luiz Ricardo Mattos Teixeira Cavalcante ${ }^{1}$ \\ Adriano Leal Bruni ${ }^{2}$ \\ Fábio José Mota Costa ${ }^{3}$
}

\section{Resumo}

O objetivo deste trabalho é confrontar o desempenho de uma carteira teórica formada pelas ações que compõem o Índice de Sustentabilidade Empresarial (ISE) com o desempenho das carteiras teóricas que formam o Índice Bovespa (Ibovespa) e o Índice Brasil (IBrX). Foram empregadas as séries de dados divulgados pela Bovespa e, no caso, do ISE, adicionalmente, retroagiu-se o índice para o período anterior a sua criação usando uma carteira de referência. Do ponto de vista metodológico, o trabalho apóia-se (a) na comparação dos retornos acumulados, retornos médios e desvios padrão do ISE, do Ibovespa e $\mathrm{IBrX}$ ao longo de 345 pregões distribuídos em torno da data de criação do índice; e (b) nos testes de estacionariedade das séries que relacionam o ISE ao Ibovespa e o ISE ao IBrX. Tendo em vista a elevada participação de instituições financeiras na composição do ISE, comparou-se também o desempenho desse indicador excluindo essas instituições de sua carteira de referência. Os principais resultados são: (a) não há evidências de um desempenho superior do ISE no período posterior a sua criação; (b) há, porém, indicações de que as carteiras retroagidas do ISE apresentaram melhor desempenho no período anterior à criação do índice, sugerindo que a precificação teria ocorrido antes de sua divulgação oficial; (c) ainda assim, não foi possível identificar um momento específico que marcasse a elevação percebida nos preços; e (d) grande parte do melhor desempenho obtido pelo ISE no período que antecede sua criação pode ser creditado ao desempenho das instituições financeiras que o compõem.

Palavras-chave: Responsabilidade Social Corporativa, Preços das Ações, Eficiência de Mercado.

\footnotetext{
1 Professor Doutor da Faculdade de Economia, Administração, Contabilidade e Ciência da Informação e Documentação - Universidade de Brasília - Universidade de Brasília, UnB. E-mail: lrcavalcante@ unb.br

${ }^{2}$ Professor Doutor da Escola de Administra da Universidade Federal da Bahia - EAUFBA. E-mail: albruni@ufba.br

3 Mestre pela Escola de Administração da Universidade Federal da Bahia - EAUFBA. E-mail: fcosta@brandconsultores.com.br
} 


\begin{abstract}
The objective of this paper is to confront the performance of a theoretical portfolio consisted of stocks market that make up the Corporate Sustainability Index (ISE) with performance of the theoretical portfolios that comprise the Bovespa Index (Ibovespa) and Brazil Index (IBrX). There were used the series of data disclosed by the Bovespa and in the case of ISE, in addition, retroacted the index for the prior period to its creation by using a portfolio of reference. From the methodological point of view, the work is based (a) in the comparison of cumulative returns, average returns and standard deviations of ISE, the Ibovespa and IBrX over 345 sessions spread around the date of creation of the index, and (b ) in tests of stationarity of the series that relate the ISE to the Ibovespa and ISE to IBrX. In view of the high participation of financial institutions in the composition of the ISE, it was also compared the performance of this indicator excluding these institutions from its portfolio of reference. The main results are: (a) there is no evidence of superior performance of the ISE in the period after its creation, (b)there is, however, indications that the retroactive effect of the ISE portfolio showed better performance in the period before the creation of the index, suggesting that the pricing would have occurred before its official release, (c) thus, it was not possible to identify a particular moment that marks a noticeable increase in prices, and (d) much of the improved performance obtained by the ISE in the period preceding its creation can be credited to the performance of the financial institutions which compose it.
\end{abstract}

Keywords: Corporate Social Responsibility Practices; Share Prices; Market Efficiency.

\title{
1. Introdução
}

A estreita associação entre as atividades de intermediação financeira e o desenvolvimento econômico tem sido amplamente reconhecida (LEVINE, 1997). É também razoavelmente consensual que a eliminação de assimetrias de informação entre potenciais investidores e demandantes de capital contribui para o desenvolvimento dos mercados financeiros (STIGLITZ; WEISS, 1981). Com base nessa percepção, indicadores de governança têm se disseminado nos mercados de ações, visando prover aos investidores maiores níveis de informação sobre os ativos. Nesse caso, esperam-se, ao menos teoricamente, impactos positivos sobre o desempenho corporativo dos papéis, uma vez que o atendimento aos critérios que compõem os índices de governança garantiria aos investidores menores níveis de incerteza quanto ao fato de que as empresas estariam sendo geridas efetivamente de acordo com os interesses de seus proprietários. Em resumo, o cumprimento dos requisitos para inclusão em índices de governança reduziria a volatilidade dos papéis por garantir maiores níveis de evidenciação das ações adotadas pelos gestores.

Em paralelo aos movimentos indicados acima, vem se disseminando, no período recente, a percepção quanto à importância das ações de responsabilidade social e de sustentabilidade ambiental adotadas pelas empresas. Atentos a esses movimentos, os mercados financeiros têm buscado criar, também, índices capazes de refletir o engajamento das empresas em iniciativas 
dessas naturezas. Porém, os impactos dessas ações sobre o desempenho corporativo são ainda controversos. Pode-se argumentar, por um lado, que ações de responsabilidade social e ambiental representariam custos adicionais e tenderiam a reduzir a remuneração que poderia ser auferida pelos acionistas. Trata-se, em essência, da chamada "teoria dos shareholders", que remonta aos argumentos apresentados por Friedman (1970) há quase quarenta anos. Em oposição, de acordo com a "teoria dos stakeholders", a adoção de práticas dessa natureza contribuiria para a obtenção de melhores desempenhos financeiros. Esse efeito poderia ser creditado à redução de eventuais passivos trabalhistas ambientais e à manutenção de uma melhor imagem da corporação (que se reverteria em benefícios como a prática de preços superiores aos de mercado). Esse debate tem motivado investigações de natureza empírica cuja questão fundamental é a associação entre índices de responsabilidade social ou sustentabilidade ambiental e desempenho corporativo nas dimensões de risco e retorno.

O recente lançamento, no final de 2005, do chamado Índice de Sustentabilidade Empresarial (ISE) pela Bolsa de Valores de São Paulo (Bovespa) permite que se façam análises dessa natureza para o mercado brasileiro. Este trabalho tem, assim, o objetivo de confrontar o desempenho de uma carteira teórica formada pelas ações que compõem o Índice de Sustentabilidade Empresarial (ISE) com o desempenho das carteiras teóricas que formam o Índice Bovespa (Ibovespa) e o Índice Brasil (IBrX). Do ponto de vista metodológico, o trabalho apóia-se (a) na comparação dos retornos acumulados, retornos médios e desvios padrão do ISE, do Ibovespa e IBrX ao longo de 345 pregões distribuídos em torno da data de criação do índice; e (b) nos testes de estacionariedade das séries que relacionam o ISE ao Ibovespa e o ISE ao IBrX. O método adotado aqui é, portanto, uma alternativa ao estudo de evento tradicionalmente aplicado em trabalhos dessa natureza. O trabalho está estruturado em mais quatro seções além desta introdução. Na Seção 2, apresentam-se os fundamentos teóricos necessários para a análise e uma breve revisão bibliográfica da associação entre índices de responsabilidade social e ambiental e desempenho corporativo. Em seguida, na terceira seção, discutem-se a metodologia e os dados empregados no trabalho. Os resultados são apresentados na Seção 4. Finalmente, na quinta seção indicam-se as principais conclusões da pesquisa.

\section{Fundamentos Teóricos}

Os livros-texto de finanças são unânimes em reconhecer que os ativos são, ao menos em tese, precificados com base no valor presente nos fluxos de caixa futuros a serem gerados (ROSS; WESTERFIELD; JAFFE, 1995; GITMAN, 1997; DAMODARAN, 1998; BRIGHAM; HOUSTON, 2004). Nesse sentido, o valor $V$ de um ativo é dado pela Equação 01 abaixo:

$$
V=\sum_{i=1}^{n} \frac{F C_{i}}{1+w a c c} \quad \text { (Eq. 01) }
$$

É evidente, portanto, que quaisquer alterações nas variáveis empregadas para estimar os fluxos de caixa $F C_{i}$ ou o custo de capital wacc usado para descontá-los devem alterar, também, o valor atribuído aos ativos. Naturalmente, a "teoria dos shareholders" sugere que ações de responsabilidade social e ambiental representariam custos adicionais, reduzindo os valores estimados de $F C_{i}$ e, portanto, o valor do ativo. Já para a "teoria dos stakeholders", a adoção de práticas dessa natureza contribuiria para a elevação dos valores estimados de $F C_{i}$ (devido à 
redução de eventuais passivos trabalhistas e ambientais e à manutenção de uma melhor imagem da corporação com conseqüente ampliação do market share e dos preços praticados) e para a redução do wacc devido aos menores níveis de risco percebidos pelos investidores. Entretanto, autores como Epstein e Roy (2000, p. 39) reconhecem as dificuldades inerentes à estimativa dos custos e benefícios de ações ambientais. Nos termos desse autores, "a estimativa da geração de caixa de um projeto esperada para o futuro é uma tarefa complicada, especialmente no caso de custos e benefícios associados ao meio ambiente, que sempre apresentam grande incerteza e longa duração" (EPSTEIN; ROY, 2000, p. 39).

A disseminação do debate quanto à importância das ações de responsabilidade social e de sustentabilidade ambiental adotadas pelas empresas e as dificuldades associadas à estimativa dos impactos diretos dessas ações sobre os fluxos de caixa e sobre o custo de capital vêm motivando, no período recente, pesquisas destinadas a averiguar a existência (ou não) de uma associação entre o engajamento nessas atividades e os resultados corporativos alcançados. Uma revisão da produção teórica recente sobre o tema, contudo, indica que persistem ainda controvérsias sobre essa questão. De uma forma geral, essas controvérsias apóiam-se no contraponto entre as chamadas "teoria dos shareholders" e "teoria dos stakeholders" mencionadas na introdução deste artigo.

Na verdade, o debate remonta à década de 1970, quando Moskowitz (1972, apud ALEXANDER; BUCHHOLTZ, 1978) argumentava que empresas engajadas em atividades de responsabilidade social teriam apresentado melhores retornos do que índices de mercado como o Dow-Jones, enquanto Vance (1975, apud ALEXANDER; BUCHHOLTZ, 1978) obtinha correlações negativas entre ações de performance das ações no mercado financeiro e ações de responsabilidade social. Os próprios Alexander e Buchholtz (1978), que se propuseram a aprofundar essa análise (controlando, inclusive, pelo risco das aplicações, ao contrário dos primeiros estudos citados), concluíram que

[...] o nível de responsabilidade social analisado por profissionais do mercado financeiro e estudantes não apresentou nenhuma relação significativa com a performance no mercado acionário. Além disso, aparentemente, não existe relação significativa entre o nível de risco da ação e o seu grau de sustentabilidade social.

Mais tarde, Ullmann (1985) concluiria que (a) a ausência de fundamentação teórica, (b) a definição inadequada dos termos empregados e (c) deficiências nas bases de dados empíricos empregadas explicaria porque os resultados obtidos em diferentes estudos se mantinham inconsistentes entre si.

Garz, Volk e Gilles (2002), ao estender a análise para a questão da sustentabilidade, entretanto, argumentam enfaticamente que "sustainability pays off". Esses autores propõem a formação de carteiras de empresas sustentáveis apropriando análises de fronteira eficiente de Markowitz (1952). Tsoutsoura (2004) indica que a responsabilidade social corporativa está positivamente relacionada ao alcance de melhores desempenhos financeiros e essa relação é estatisticamente significativa, suportando, portanto, a visão de que desempenho socialmente responsável pode estar associado à melhoria no lucro das empresas. A revisão da literatura apresentada por Curran (2005) indica que $70 \%$ dos estudos apontariam uma relação positiva e 
estatisticamente significativa entre responsabilidade social e performance financeira. Contudo, os estudos empíricos dessa autora "demonstram as dificuldades existentes para fornecer evidências estatísticas fortes acerca da associação entre responsabilidade social corporativa e performances financeiras".

Estudos recentes feitos para o caso brasileiro não chegam, da mesma forma, a um consenso sobre o tema. Com efeito, Soares (2003), que realizou um estudo para o período entre 2001 e 2003, concluiu que o Índice de Governança Corporativa havia apresentado melhores resultados do que o Ibovespa, o IBrX e o Índice de Energia Elétrica (IEE) no intervalo considerado. Por outro lado, Borba (2005) argumenta que, no período entre 2000 e 2002, (a) não existe relação entre as variáveis de desempenho social e financeiro corporativos; (b) contudo, por diversas vezes ocorreram relações positivas entre indicadores financeiros e desempenho social; (c) os resultados encontrados não são suficientes para afirmar que um melhor ou pior desempenho social corporativo afetaria o desempenho financeiro, para melhor ou pior; e (d) os resultados estatísticos obtidos não foram significativos para afirmar haver relação negativa entre desempenho social corporativo e desempenho financeiro.

Em que pese a persistência da controvérsia, há autores que, adotando métodos mais dedutivos do que indutivos (isto é, apoiando menos em dados de desempenho e mais em sua expectativa com base nas preferências declaradas dos stakeholders), defendem o ponto de vista de que as políticas corporativas de sustentabilidade, ao contribuírem para definir os novos contornos de uma boa governança (incluindo a perspectiva social e ambiental) confeririam maiores níveis de competitividade e rentabilidade. Esse é o caso, no Brasil, de Barontini (2005) ou de Oliveira (2002). Esse último argumenta que

[...] empresas mais responsáveis do ponto de vista ambiental valorizam substancialmente mais que a média. Além do mais, já existem diversos fundos de investimento que priorizam investimentos em empresas ambientalmente ou socialmente responsáveis de acordo com critérios e redes de informações criadas por eles.

Waage (2004) atribui percepções dessa natureza ao fato de que os impactos negativos na reputação de empresas que violam direitos humanos ou que se envolvem em questões ambientais têm ficado cada vez mais evidentes, motivando a inclusão, em seus resultados finais, dos retornos ecológicos e sociais (WAAGE, 2004).

Proposições dessas naturezas são, frequentemente, apoiadas em pesquisas de opinião. A McKinsey \& Co, em parceria com a Global Corporate Governance Forum, realizou uma pesquisa junto a investidores entre abril e maio de 2002, apurando que estes estariam dispostos a pagar entre $11 \%$ e $41 \%$ a mais por ações de companhias que adotam melhores práticas de gestão e transparência. No Brasil, a pesquisa indica que os investidores pagariam $24 \%$ a mais por ações de companhias com este perfil (MCKINSEY, 2002). Em outra pesquisa realizada pela BITC and Research International em 2003, revelou que $86 \%$ dos consumidores concordavam em, quando o preço e a qualidade são equivalentes, eles estariam mais propensos a adquirir um produto associado a uma "causa", $61 \%$ trocariam de loja pela mesma razão e $86 \%$ teriam uma imagem mais positiva de uma companhia se percebesse que ela estava realizando algo para fazer um mundo melhor (HANCOCK, 2005). Da mesma forma, uma pesquisa realizada pela CSR Europe 
and Euronext identificou que $51 \%$ dos gestores de fundos e $37 \%$ dos analistas financeiros pagariam um prêmio em companhias socialmente responsáveis (HANCOCK, 2005). Para esse mesmo autor, cada vez mais clientes estão distinguindo empresas "responsáveis" daquelas "irresponsáveis" e governos e reguladores estão cada vez mais propensos a emitir licenças e concessões às empresas que tenham comprometimento com a responsabilidade corporativa.

A expectativa de aumento da procura por ações de companhias que adotam práticas relacionadas à sustentabilidade é atribuída, pelo site Sustainability-Index (2006), que acompanha os Dow Jones Sustainability Indexes (DJSI) da Bolsa de Nova York, a dois fatores:

a) O conceito de sustentabilidade corporativa é atrativo para os investidores porque tem como objetivo aumentar o valor das ações no longo prazo;

b) Líderes que adotam práticas de sustentabilidade mais provavelmente demonstrarão um desempenho superior e favorável na relação risco-retorno, e um número crescente de investidores está convencido que a sustentabilidade é um catalisador para uma gestão sábia e disciplinada, e, desse modo, um fator crucial de sucesso.

\section{Aspectos Metodológicos}

Do ponto de vista metodológico, este trabalho apóia-se (a) na comparação dos retornos acumulados, retornos médios e desvios padrão do ISE, do Ibovespa e $\mathrm{IBrX}$ ao longo de do período situado no entorno da criação do índice em 30 de novembro de 2005; e (b) nos testes de estacionariedade das séries que relacionam o ISE ao Ibovespa e o ISE ao IBrX. Tendo em vista a elevada participação de instituições financeiras na composição do ISE, comparou-se também o desempenho desse indicador excluindo essas instituições de sua carteira de referência. Nesta seção, portanto, discutem-se os procedimentos metodológicos requeridos para a comparação dos retornos acumulados, retornos médios e desvios padrão (Subseção 3.1), a aplicação dos testes de estacionariedade (Subseção 3.2) e os dados empregados na análise, bem como os procedimentos adotados para a remoção das instituições financeiras da carteira teórica do ISE (Subseção 3.3).

\subsection{Comparação de Retornos Acumulados, Retornos Médios e Desvios Padrão}

Conforme amplamente discutido nos livros-texto de finanças (ROSS; WESTERFIELD; JAFFE, 1995; GITMAN, 1997; DAMODARAN, 1998; BRIGHAM; HOUSTON, 2004), o Modelo de Precificação de Ativos de Capital ou Capital Asset Pricing Model (CAPM) desenvolvido por Sharpe, Litner e Mossin estabelece uma relação entre o retorno esperado de um ativo e seu nível de risco. O CAPM baseia-se na seguinte equação:

$$
E\left(R_{j}\right)=R_{f}+\left[E\left(R_{M}\right)-R_{f}\right] \beta_{j} \quad(\text { Eq. 02) }
$$

Onde $E\left(R_{j}\right)$ é a expectativa de retorno da ação ou da carteira de ações, $R_{f}$ : é o retorno do ativo livre de risco ${ }^{1}, E\left(R_{M}\right)$ é o retorno esperado do mercado e $\beta_{\mathrm{j}}$ é o grau de volatilidade de um título em relação às mudanças do mercado. Os livros-texto de finanças costumam definir $\beta_{\mathrm{j}}$ como a inclinação da reta de regressão dos retornos de mercado e dos retornos do ativo j. Embora a aplicação empírica do $C A P M$ desperte ainda debates de diversas naturezas, pode-se afirmar, com base na Equação 02, que, de uma forma geral, não se pode comparar diretamente os retornos de dois ativos ou carteiras de ativos sem levar em conta o risco (ou a volatilidade) de cada um deles. 
Essa observação tem implicações metodológicas evidentes neste trabalho, uma vez que, ao se confrontar o desempenho do ISE em relação ao desempenho do mercado não se deve perder de vista seus níveis de oscilação ao longo do período para qual se estabeleceu a comparação.

\subsection{Teste de Estacionariedade}

Uma forma alternativa de constatar o deslocamento do ISE em relação ao Ibovespa e ao IBrX ao longo do período considerado é verificar a evolução da relação ISE/Ibovespa ou ISE/IBrX (que, em função do padrão de normalização adotado neste artigo, converge para 1,00 na data de criação do índice) e testar sua estacionariedade em nível e em primeira diferença. A essência do argumento é que séries estacionárias em nível indicam a ausência de deslocamento da carteira teórica do ISE em relação ao Ibovespa ou ao IbrX, ao passo que séries auto-regressivas de primeira ordem (isto é, para as quais há uma tendência de que $y_{t-1}$ seja inferior a $y_{t}$ mais uma perturbação aleatória) têm uma tendência ascendente (ou descendente, conforme o sinal obtido) e demonstram um deslocamento do numerador em relação ao denominador (isto é, do ISE em relação ao Ibovespa ou ao IbrX).

O método aqui adotado é uma alternativa ao estudo de evento tradicionalmente aplicado em trabalhos dessa natureza. Como se sabe, o objetivo do estudo de eventos é medir o efeito ocasionado por um novo fato econômico sobre o valor de um ativo. $\mathrm{O}$ estudo de eventos permite que se comparem os retornos projetados dos ativos que deveriam ser observados na ausência do evento com os retornos reais identificados (CAMPBELL; LO; MACKINLAY, 1997, p. 149-180; BRUNI, 2002). Caso os retornos reais sejam maiores que os esperados, pode-se afirmar que houve impacto positivo sobre os preços dos ativos.

É evidente que retornos anormais sistematicamente positivos levariam a relação entre o ISE e as carteiras de referência a exibir uma tendência ascendente que pode ser capturada pelo teste de estacionariedade proposto. Da mesma forma, retornos anormais sistematicamente negativos estariam associados a uma tendência descendente da relação entre o ISE e as carteiras de referência. Em outras palavras, salvo pela composição de suas carteiras teóricas (que, no caso do estudo de evento, atribui o mesmo peso a cada ação que o compõe, enquanto o teste de estacionariedade proposto mantém os pesos relativos dos ativos que formam a carteira teórica do ISE), os dois métodos devem levar a conclusões idênticas.

\subsection{Dados Empregados}

Criado em 30 de novembro de 2005, o Índice de Sustentabilidade Empresarial (ISE) mede o retorno total de uma carteira teórica composta por papéis (escolhidos entre os mais líquidos da Bovespa) melhor classificados em termos de responsabilidade social e ambiental e de sustentabilidade. Os critérios de seleção e classificação adotados são definidos pelo Centro de Estudos de Sustentabilidade da Fundação Getúlio Vargas (CES-FGV) e referendados pelo Conselho Deliberativo do ISE, composto pela própria Bovespa, pela International Finance Corporation (IFC), por associações como a Associação Brasileira das Entidades Fechadas de Previdência (ABRAPP), a Associação dos Analistas e Profissionais de Investimento do Mercado de Capitais (APIMEC) e a Associação Nacional dos Bancos de Investimento (ANBID), por organizações não governamentais como o Instituto Ethos e o Instituto Brasileiro de Governança Corporativa (IBGC) e pelo Ministério do Meio Ambiente. O questionário desenvolvido pelo 
CES-FGV parte do conceito do "triple bottom line" que envolve a avaliação de elementos ambientais, sociais e econômico-financeiros de forma integrada. De acordo com a Bovespa (2006), as respostas das companhias são analisadas usando a ferramenta estatística "análise de clusters", que identifica os grupos de empresas com desempenhos similares e aponta o grupo com melhor desempenho geral. As empresas desse grupo compõem a carteira final do ISE.

Assim, em virtude da própria natureza do ISE, dois aspectos devem ser considerados na análise da próxima seção. Em primeiro lugar, é preciso ter em mente que o ISE propõe-se a ser um índice de sustentabilidade empresarial (e não somente de sustentabilidade ambiental), considerando dimensões econômico-financeiras, de governança e de responsabilidade social e ambiental. Um segundo aspecto é que, em virtude dos critérios considerados para a inclusão de ativos no ISE, instituições financeiras acabam prevalecendo na composição do ISE. Com efeito, conforme se observa no Anexo 1, somente o Bradesco, o Itaú, a Itaúsa e o Unibanco representam quase $60 \%$ da carteira do ISE.

É importante registrar, ainda, que as séries históricas utilizadas neste trabalho foram obtidas diretamente no site da Bovespa. Em particular, no caso do ISE, retroagiu-se o índice para o período anterior a sua criação usando uma carteira de referência correspondente à carteira teórica média anual do ISE válida para o período entre dezembro de 2005 e dezembro de 2006 (divulgada no site da Bovespa). Para retroagir os índices, os preços das ações que compõem foram obtidos junto a Economática. Em virtude da composição da carteira teórica média utilizada nesse procedimento, foi possível retroagir o ISE por um período correspondente a 172 pregões anteriores a sua criação, uma vez que não seria possível calcular o retorno da carteira em datas anteriores a 24 de março de 2005 (em função da inexistência, antes dessa data, das cotações de algumas ações que compõem o índice) $)^{2}$. Optou-se então por um horizonte total de 345 pregões situados em torno da data de criação do ISE (isto é, 172 pregões anteriores a 30 de novembro de 2005 e 172 pregões após essa data). Procedimentos análogos permitiram, também, o cálculo de um índice de sustentabilidade empresarial excluindo os intermediários financeiros de sua composição.

\section{Resultados}

Nesta seção, discutem-se os resultados obtidos a partir da metodologia explicitada na Seção 3.

\subsection{Período Posterior à Criação do ISE}

A Figura 1 a seguir mostra a evolução de números índices normalizados para 1000 (na data da criação do ISE) relativos ao próprio ISE, ao Ibovespa e ao IBrX ao longo dos 172 pregões posteriores à criação do ISE. 


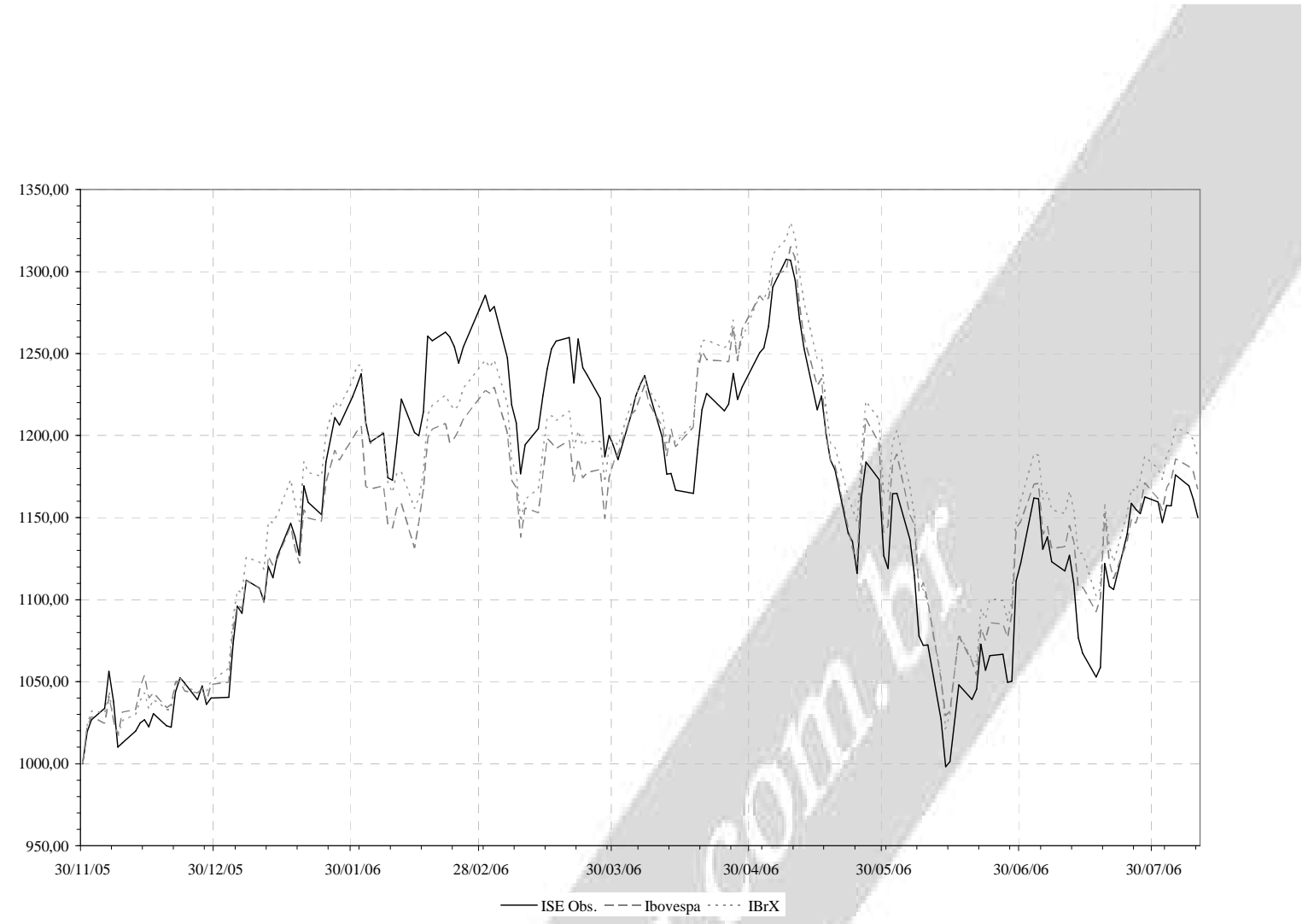

Figura 1: Evolução do ISE, do Ibovespa e do IBrX entre 30/11/2005 e 09/08/2006

Fonte: elaboração própria com base em dados disponíveis no site da Bovespa (http://www.bovespa.com.br).

A simples observação do gráfico revela não ter havido um deslocamento representativo do ISE em relação ao Ibovespa e ao IBrX. Essa percepção é amparada pelos dados indicados na Tabela 1, que indicam que, no período que se inicia em 30/11/2005, o ISE teve um retorno acumulado de $15,00 \%$ enquanto o Ibovespa teve um retorno acumulado de $16,73 \%$ e o IBrX de $18,65 \%$. Da mesma forma, o retorno médio aritmético do ISE foi levemente inferior ao dos demais indicadores. Em suma, uma analise rápida para a hipótese $\bar{r}_{\text {ISE }}>\bar{r}_{\text {Ibovespa }}$ ou para $\bar{r}_{I S E}>\bar{r}_{I B X}$ revela-se claramente não significativa do ponto de vista estatístico. Um outro aspecto a ser considerado é que, além de ter apresentados taxas de retorno inferiores, o ISE mostrou-se mais volátil do que o Ibovespa e o IBrX, conforme indicado pelos desvios padrão obtidos para cada um dos indicadores.

Tabela 1: Desempenho Médio do ISE, do Ibovespa e do IBrX entre 30/11/2005 e 09/08/2006

\begin{tabular}{lccc}
\hline & ISE Obs. & Ibovespa & IBrX \\
\hline Retorno Acumulado & $15,00 \%$ & $16,73 \%$ & $18,65 \%$ \\
\hline Retorno Médio & $0,0966 \%$ & $0,1031 \%$ & $0,1119 \%$ \\
\hline Desvio Padrão & $1,7594 \%$ & $1,6292 \%$ & $1,5851 \%$ \\
\hline Fonte: elaboração própria com base em dados disponíveis no site da Bovespa (http://www.bovespa.com.br).
\end{tabular}

Em suma: no período posterior à criação do índice, não há evidências de desempenho superior do ISE em relação ao Ibovespa e ao IBrX. Além disso, o ISE revelou-se mais volátil do que esses dois outros índices no período considerado. 


\subsection{Período Anterior à Criação do ISE}

A discussão apresentada na Seção 2 e a não-identificação de um desempenho superior do ISE no período posterior a sua criação sugerem que uma eventual precificação das informações contidas no índice pode ter ocorrido antes da data de divulgação oficial do índice. Essa proposição apóia-se no fato de que os anúncios sobre a criação do índice remontam a alguns meses antes de dezembro de 2005 e os agentes poderiam ter começado a distinguir as empresas sustentáveis daquelas não sustentáveis desde aquele momento.

É claro que uma análise dessa natureza pressupõe a retroação do ISE para o período anterior a sua criação. Esse procedimento, que, em função de variações na carteira teórica do índice pode resultar em erros, não ocasionou, na presente análise, desvios significativos. Com efeito, durante o período posterior à criação do ISE (durante o qual se pode comparar o ISE divulgado pela Bovespa e o ISE calculado), os desvios, embora crescentes, situaram-se em níveis inferiores a $3 \%)$.

Com base na série do ISE calculado, portanto, foi possível observar que, nos 172 pregões anteriores a 30/11/2005, o ISE normalizado passou de um patamar normalizado inferior a 700 para 1000, enquanto os índices de mercado (também normalizados) passaram de um patamar em torno de 800 para 1000 (Figura 2).

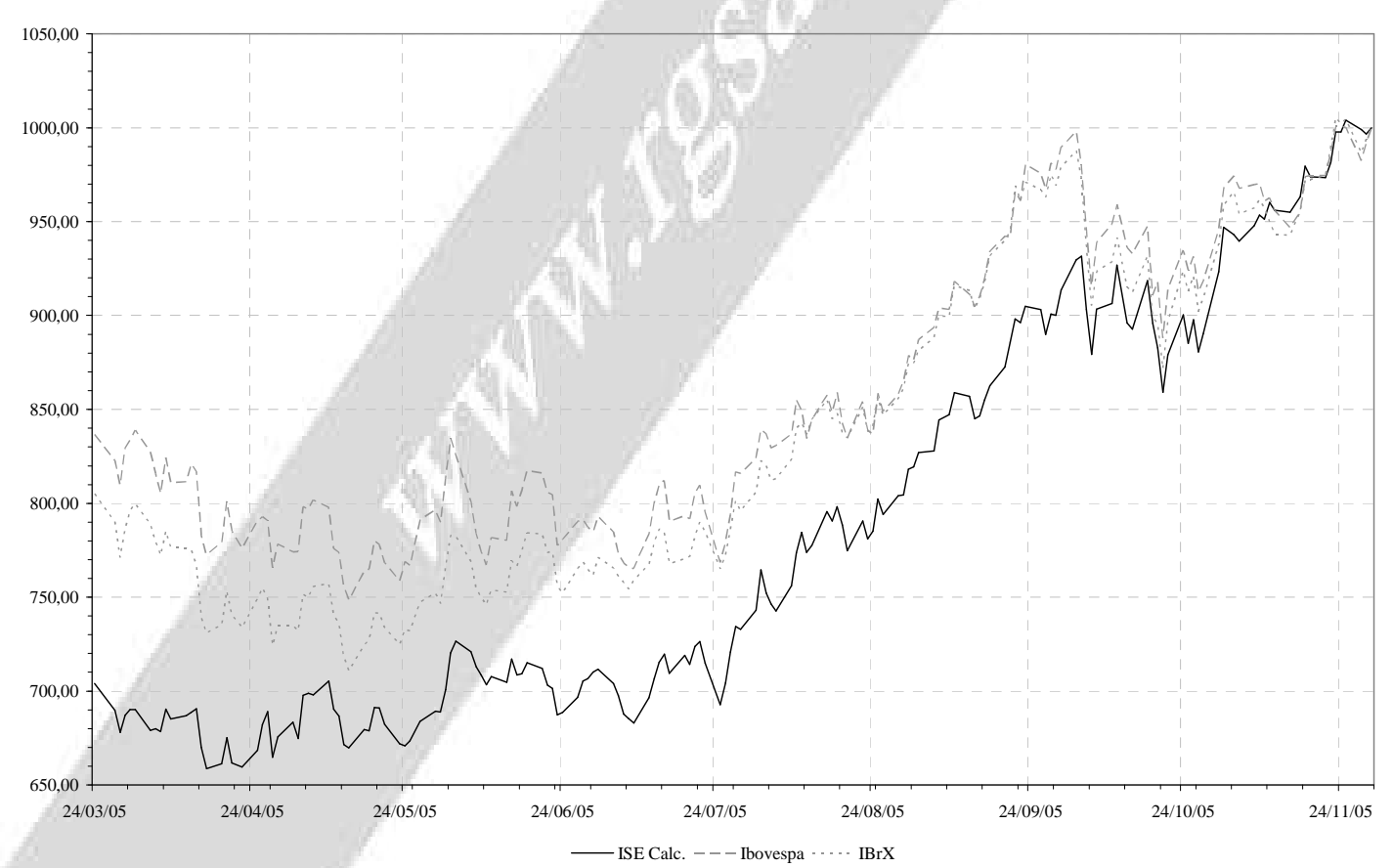

Figura 2: Evolução do ISE, do Ibovespa e do IBrX entre 24/03/2005 e 30/11/2006

Fonte: elaboração própria com base em dados disponíveis no site da Bovespa (http://www.bovespa.com.br).

Essa percepção é confirmada ao se observar a Tabela 2, que indica que, entre 24/03/2005 e 30/11/2005, o ISE teve um retorno acumulado de $42,04 \%$ enquanto o Ibovespa e o $\mathrm{IBrX}$ acumularam retornos de menos de $20 \%$ e de cerca de $24 \%$, respectivamente. Da mesma forma, enquanto o retorno médio do ISE situou-se em $0,2146 \%$, o retorno médio apresentado pelo 
Ibovespa e pelo IBrX situou-se em torno da metade desse valor. É interessante notar que o melhor desempenho apresentado pelo ISE não pode ser creditado à exposição a maiores níveis de risco, uma vez que o desvio padrão desse indicador é inferior àquele do Ibovespa e do IBrX.

Tabela 2: Desempenho Médio do ISE, do Ibovespa e do IBrX entre 24/03/2005 e 30/11/2006

\begin{tabular}{lccc}
\hline & ISE & Ibovespa & IBrX \\
\hline Retorno Acumulado & $42,04 \%$ & $19,53 \%$ & $24,22 \%$ \\
\hline Retorno Médio & $0,2146 \%$ & $0,1166 \%$ & $0,1364 \%$ \\
\hline Desvio Padrão & $1,4423 \%$ & $1,6051 \%$ & $1,4352 \%$ \\
\hline
\end{tabular}

Fonte: elaboração própria com base em dados disponíveis no site da Bovespa (http://www.bovespa.com.br).

Uma forma interessante de constatar o deslocamento do ISE em relação ao Ibovespa e ao IBrX ao longo do período considerado é verificar a evolução da relação ISE/Ibovespa ou ISE/IBrX que, em função do padrão de normalização adotado, converge para 1 na data de criação do ISE.

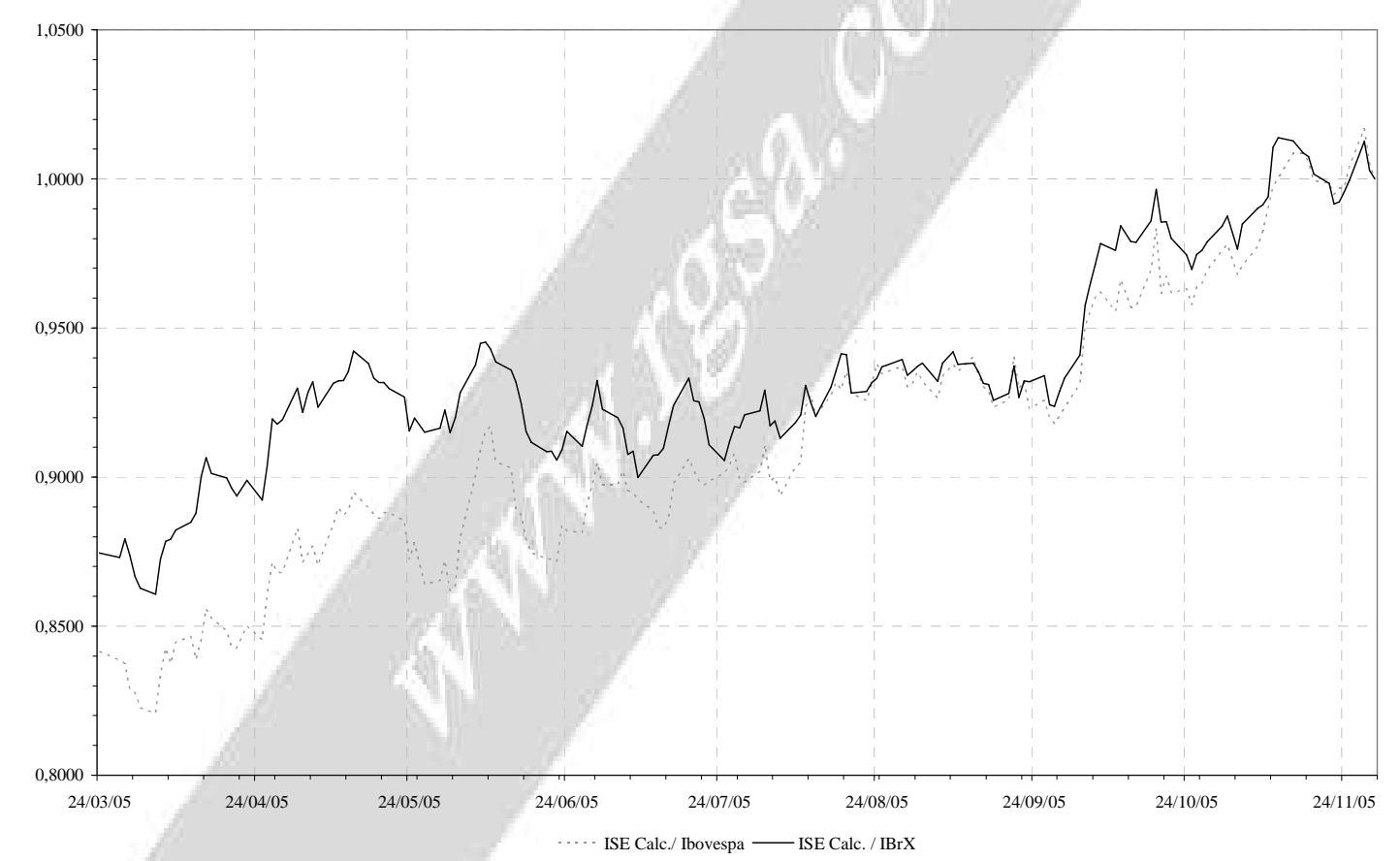

Figura 3: Evolução da Relação ISE / Ibovespa e ISE / IBrX entre 24/03/2005 e 30/11/2006

Fonte: elaboração própria com base em dados disponíveis no site da Bovespa (http://www.bovespa.com.br).

As séries indicadas na Figura 3 reafirmam a percepção de descolamento entre o ISE e o Ibovespa e o IBrX, uma vez que sugerem a existência de uma tendência. A verificação estatística dessa tendência pode ser feita através de um teste estacionariedade das séries ISE/Ibovespa e ISE/IBrX em nível e em primeira diferença. Os principais resultados (obtidos através do software -views) estão indicados na Tabela 3 abaixo: 
Tabela 3: Testes de Estacionariedade ISE/Ibovespa e ISE/IBrX entre 24/03/2005 e 30/11/2006

\begin{tabular}{|c|c|c|c|c|c|}
\hline & & \multicolumn{2}{|c|}{ ISE / Ibovespa } & \multicolumn{2}{|c|}{ ISE/IBrX } \\
\hline & & Level & $\begin{array}{c}\text { First } \\
\text { Difference }\end{array}$ & Level & $\begin{array}{c}\text { First } \\
\text { Difference }\end{array}$ \\
\hline $\begin{array}{l}\text { Augmented Dickey- } \\
\text { Fuller test statistic }\end{array}$ & & $-0,70998$ & $-13,1233$ & $-1,07737$ & $-12,186$ \\
\hline \multirow[t]{3}{*}{ Test critical values: } & $1 \%$ level & $-3,46852$ & $-3,46875$ & $-3,46852$ & $-3,46875$ \\
\hline & $5 \%$ level & $-2,87821$ & $-2,87831$ & $-2,87821$ & $-2,87831$ \\
\hline & $10 \%$ level & $-2,57574$ & $-2,57579$ & $-2,57574$ & $-2,57579$ \\
\hline Akaike info criterion & & $-7,01687$ & $-7,00981$ & $-7,32988$ & $-7,32193$ \\
\hline Schwarz criterion & & $-6,98027$ & $-6,97307$ & $-7,29328$ & $-7,28519$ \\
\hline
\end{tabular}

Fonte: elaboração própria com base em dados disponíveis no site da Bovespa (http://www.bovespa.com.br).

Os resultados confirmam que, de fato, houve um deslocamento sistemático do ISE em relação ao Ibovespa e ao IBrX no período. Com efeito, quando o teste de estacionariedade é aplicado em nível, os resultados são pouco significativos do ponto de vista estatístico (basta verificar que, tanto com o Ibovespa como com o IBrX, a estatística do teste de Dickey-Fuller aumentado é inferior aos valores críticos, mesmo que se tolerasse um intervalo de confiança de apenas $90 \%$ ). Por outro lado, em ambos os casos, quando o teste é aplicado em primeira diferença (isto é, admitindo um crescimento sistemático da relação ISE/Ibovespa ou ISE/IBrX), os resultados são claramente significativos a $99 \%$ de confiança.

\subsection{O Comportamento do ISE exclusive os Intermediários Financeiros}

A excessiva concentração da carteira teórica do ISE no segmento de intermediação financeira motivou a realização de testes adicionais para verificar o desempenho do ISE exclusive essas instituições. Esses testes se justificam por quatro razões principais: (a) os intermediários financeiros representam mais de $60 \%$ da carteira teórica do ISE (ver Anexo 1); (b) os impactos ambientais desse tipo de empresa são intrinsecamente menores do que aqueles observados no segmento industrial (em virtude da própria natureza desses segmentos); (c) o porte elevado dessas instituições pode favorecer seu engajamento em ações de responsabilidade social, uma vez que os recursos destinados a essas ações podem ser menos representativos quando confrontados com o faturamento dos intermediários financeiros; e (d) o desempenho dos intermediários financeiros tem sido particularmente positivo ao longo de 2005 e 2006.

A Tabela 5 resume o desempenho do ISE exclusive Intermediários Financeiros nos períodos anterior e posterior à criação desse índice. 
Tabela 5: Desempenho Médio do ISE (exclusive Intermediários Financeiros), do Ibovespa e do IBrX entre 24/03/2005 e 09/08/2006

\begin{tabular}{lcccccc}
\hline & \multicolumn{2}{c}{ Período anterior à Criação do ISE } & \multicolumn{2}{c}{ Período posterior à Criação do ISE } \\
\hline & $\begin{array}{c}\text { ISE excl. } \\
\text { Int. Fin. }\end{array}$ & Ibovespa & IBrX & $\begin{array}{c}\text { ISE excl. } \\
\text { Int. Fin. }\end{array}$ & Ibovespa & IBrX \\
\hline Retorno Acumulado & $23,43 \%$ & $19,53 \%$ & $24,22 \%$ & $21,96 \%$ & $16,73 \%$ & $18,65 \%$ \\
\hline Retorno Médio & $0,1312 \%$ & $0,1166 \%$ & $0,1364 \%$ & $0,1242 \%$ & $0,1031 \%$ & $0,1119 \%$ \\
\hline Desvio Padrão & $1,3254 \%$ & $1,6051 \%$ & $1,4352 \%$ & $1,3288 \%$ & $1,6292 \%$ & $1,5851 \%$ \\
\hline
\end{tabular}

Fonte: elaboração própria com base em dados disponíveis no site da Bovespa (http://www.bovespa.com.br).

Em linhas gerais, os dados indicados na Tabela 5 indicam que o melhor desempenho apresentado pelo ISE no período anterior a sua criação não é observado quando o índice é calculado sem as instituições financeiras. Isso implica dizer que grande parte do melhor desempenho obtido pelo ISE no período anterior a 30/11/2005 pode ser creditado ao desempenho dos intermediários financeiros que o compõem. Por outro lado, o desempenho inferior apresentado pelo ISE no período posterior a sua criação não é observado no ISE exclusive instituições financeiras.

\section{Conclusões}

Ao longo deste trabalho, buscou-se confrontar o desempenho de uma carteira teórica formada pelas ações que compõem o Índice de Sustentabilidade Empresarial (ISE) com o desempenho das carteiras teóricas que formam o Índice Bovespa (Ibovespa) e o Índice Brasil (IBrX). Foram empregadas as séries de dados divulgados pela Bovespa e, no caso, do ISE, retroagiu-se o valor para o período anterior a sua criação usando uma carteira de referência. Do ponto de vista metodológico, o trabalho apoiou-se (a) na comparação dos retornos acumulados, retornos médios e desvios padrão do ISE, do Ibovespa e IBrX ao longo de 345 pregões, sendo 172 anteriores e 172 posteriores à criação do ISE em 30/11/2005; e (b) nos testes de estacionariedade das séries que relacionam o ISE ao Ibovespa e o ISE ao IBrX. Os testes de estacionariedade empregados nesse trabalho constituíram, portanto, uma alternativa ao estudo de evento tradicionalmente aplicado em trabalhos dessa natureza.

Os principais resultados obtidos foram:

a) Conforme evidenciado na Subseção 4.1, no período posterior à criação do índice, não há evidências de desempenho superior do ISE em relação ao Ibovespa e ao IBrX. Além disso, o ISE revelou-se mais volátil do que esses dois outros índices no período considerado.

b) Há, porém, indicações de que as carteiras retroagidas do ISE apresentaram melhor desempenho no período anterior à criação do índice, sugerindo que a precificação teria ocorrido antes de sua divulgação oficial.

c) Ainda assim, ainda assim, não foi possível identificar um momento específico que marcasse a elevação percebida nos preços. Com efeito, o movimento parece ter sido contínuo e não associado a um degrau específico.

d) Grande parte do melhor desempenho obtido pelo ISE no período que antecede sua criação pode ser creditado ao desempenho das instituições financeiras que o compõem. 
Os resultados aqui obtidos, entretanto, referem-se a um período ainda relativamente curto (345 pregões). Embora se pudesse supor que os fluxos futuros sejam precificados de forma automática, mercados menos eficientes podem requerer intervalos maiores para incorporar as informações contidas no ISE. Além disso, as conclusões indicam algumas limitações intrínsecas ao indicador de sustentabilidade empregado. Com efeito, a excessiva concentração do ISE em empresas de grande porte e, sobretudo, em intermediários financeiros, pode sugerir que a adesão ao índice seja empregada como estratégia de melhoria da imagem corporativa (em virtude da larga aceitação de ações de responsabilidade social e ambiental) a custos reduzidos (quando confrontados com o faturamento das empresas). Por exemplo: o atendimento aos itens indicados no questionário para adesão ao ISE apóia-se, muitas vezes, em valores fixos (e não variáveis), facilitando o investimento por empresas de grande porte e por intermediários financeiros (cujos impactos ambientais são intrinsecamente inferiores àqueles de empresas industriais). Trata-se, naturalmente, de uma hipótese que requer confirmação através de pesquisas futuras.

Finalmente, não se deve perder de vista que pesquisas futuras não podem deixar de explorar a questão da causalidade. Com efeito, pouco tem se investigado, ainda, se a adesão a ações de responsabilidade social e ambiental motivaria melhores resultados financeiros ou se seriam os melhores resultados financeiros que permitiram o engajamento nessas ações. Essa hipótese é particularmente atrativa quando se tem em mente que empresas em dificuldades usualmente ocupam-se de questões mais prementes (a gestão do caixa) e têm escassas possibilidades de engajamento em ações cujos resultados são obtidos no longo prazo. Trata-se, mais uma vez, de uma questão a ser explorada em trabalhos futuros.

\section{Referências}

ALEXANDER, Gordon J., BUCHHOLZ, Rogene A. Corporate social responsibility and stock market performance. Academy of Management Journal, v. 21, n. 3, 1978, p. 479-486.

BARONTINI, Giovanni. Responsabilidade socioambiental e profissionalismo. In: 26. CONGRESSO BRASILEIRO DOS FUNDOS DE PENSÃO, 2005, Porto Alegre. Governança Corporativa no Tripé da Sustentabilidade: Surgimento do Conceito de "Governança Climática" e seu Impacto nas Decisões de Investimento. Porto Alegre, p. 178-181, 26 a 28 out. 2005.

BORBA, Paulo de Rocha Ferreira. Relação entre desempenho social corporativo e desempenho financeiro de empresas no Brasil. 127 f. Dissertação (mestrado em administração), Faculdade de economia, administração e contabilidade, Universidade de São Paulo, São Paulo, 2005. Disponível em: <http://www.teses.usp.br/>. Acesso em 21 jan. 2006.

BOVESPA. ISE - Índice de Sustentabilidade Empresarial. Bolsa de Valores de São Paulo. Disponível em: http://www.bovespa.com.br. Acesso em: 02 fev 2006.

BRIGHAM, Eugene F.; HOUSTON, Joel F. Fundamentals of financial management. 10th ed. Mason (OH): Thomson South-Western, 2004.

BRUNI, Adriano Leal. Globalização financeira, eficiência informacional e custo de capital: uma análise das emissões de ADRs brasileiros no período de 1992-2001. 182 f. Tese (doutorado 
em administração), Faculdade de economia, administração e contabilidade, Universidade de São Paulo, São Paulo, 2002.

CAMPBELL, John Y.; LO, Andrew. W.; MACKINLAY, A. Craig. The econometrics of financial markets. Princeton, NJ: Princeton University Press, 1997.

CURRAN Marina Martin. Assessing the rate of return of the adoption of corporate social responsibility initiatives. $199 \mathrm{f}$. Tese (doutorado). Edinburgh Management School, University of Edinburgh, 2005.

DAMODARAN, Aswath. Applied corporate finance: a user manual. New York: John Wiley \& Sons, 1998.

EPSTEIN, Marc J.; ROY, Marie-Josée. Stratetigic evaluation of environmental projects in SMEs. Environmental Quality Management, v. 9, n. 3, Spring 2000.

FRIEDMAN, Milton. The Social Responsibility Of Business Is To Increase Its Profits. The New Yok Times Magazine, 13 de setembro de 1970. Disponível em: http://www.colorado.edu/studentgroups/libertarians/issues/friedman-soc-resp-business.html. Acesso em 11 out. 2006.

GARZ, Hendrik; VOLK, Claudia; GILLES, Martin. More gain than pain. SRI: Sustainability pays off. WestLB Panmure, nov. 2002.

GITMAN, Lawrence J. Princípios de administração financeira. São Paulo: Harbra, $7^{\circ}$ ed., 1997.

HANCOCK, John. Investing in corporate social responsibility: a guide to best practice, business planning \& the UK's leading companies. London: Kogan Page, 2005. 359 p. Disponível em: http://skillport.books24x7.com/book. Acesso em 21 de out. 2006.

LEVINE, Ross. Financial development and economic growth: views and agenda. Journal of Economic Literature, v. 35, n. 2, p. 688-726, 1997.

MARKOWITZ, Harry. Portfolio Selection. Journal of Finance, v. 7 , p. 77-91, 1952.

MCKINSEY \& COMPANY. Global investor opinion survey: key findings. Jul. 2002. Disponível em em: http://www.mckinsey.com.br. Acesso em: 20.jan.2006.

MOSKOWITZ, M. Choosing socially responsible stocks. Business and Society Review, v. 1, p. 71-75, 1972.

OLIVEIRA, José Puppim de. Entendendo as respostas empresariais aos desafios socioambientais no Brasil. Revista Portuguesa e Brasileira de Gestão, vol. 1, n. 1, abr./jun. 2002, p. 56-68.

ROSS, Stephen A.; WESTERFIELD, Randolph W.; JAFFE, Jeffrey F. Administração financeira. São Paulo: Atlas, $3^{\circ}$ ed., 1995. 
SOARES, Carlos Roberto Pena. O impacto da governança corporativa sobre o comportamento do preço de ações no Brasil: O caso do papel e celulose, 2000 a $2003.97 \mathrm{f}$. Dissertação (mestrado em ciências) Escola Superior de Agricultura Luiz Queiroz, Universidade de São Paulo, Piracicaba, dez. 2003. Disponível em: <http://www.teses.usp.br/>. Acesso em 21 jan. 2006.

STIGLITZ, Joseph. E.; WEISS, Andrew. Credit rationing in markets with imperfect information. The American Economic Review, v. 71, n. 3, p. 393-410, 1981.

TSOUTSOURA, Margarita. Corporate social responsibility and financial performance. Haas School of Business University of California at Berkeley. Projeto de finanças, Berkeley, California, mar. 2004. Disponível em http://www.haas.berkeley.edu/responsiblebusiness/documents/FinalPaperonCSR_PDFII.pdf. Acesso em 05 fev. 2006.

ULLMANN, Arieh A. Data in search of a theory: a critical examination of the relationships among social performance, social disclosure, and economic performance of U.S. firms. Academy of Management Review, v. 10, n. 3, 1985, p. 540-557.

VANCE, S. C. Are socially responsible corporations good investment risks? Management Review, v. 64, p. 18-24, 1975.

WAAGE, Sissel. Uma reavaliação dos negócios a partir de uma perspectiva sistêmica: a mudança para empresas e serviços financeiros pautados na sustentabilidade. Instituto Ethos Reflexão, São Paulo, ano 5, n.12, jul. 2004. 
ANEXO 1: Composição Média do ISE (dez. 2005 a dez. 2006)

\begin{tabular}{|c|c|c|c|c|}
\hline Código & & Tipo & Qtde. Teórica & Part. (\%) \\
\hline ALLL4 & ALL AMER LAT & $\mathrm{PN}$ & 1.872 .346 & 0,022 \\
\hline ALLL11 & ALL AMER LAT & UNT & 25.559 .831 & 1,419 \\
\hline ARCZ6 & ARACRUZ & PNB & 446.972 .460 & 2,275 \\
\hline BELG3 & BELGO MINEIR & $\mathrm{ON} *$ & 4.430 .367 .530 & 3,526 \\
\hline BBDC3 & BRADESCO & $\mathrm{ON}$ & 175.814 .069 & 6,496 \\
\hline BBDC4 & BRADESCO & $\mathrm{PN}$ & 456.779 .256 & 18,504 \\
\hline BBAS3 & BRASIL & ON & 55.202 .340 & 1,296 \\
\hline BRKM5 & BRASKEM & PNA & 154.968 .512 & 1,847 \\
\hline CCRO3 & CCR RODOVIAS & $\mathrm{ON}$ & 29.781 .804 & 1,193 \\
\hline CLSC6 & CELESC & PNB & 414.790 .370 & 0,355 \\
\hline CMIG3 & CEMIG & $\mathrm{ON} *$ & 11.374 .254 .351 & 0,48 \\
\hline CMIG4 & CEMIG & $\mathrm{PN} *$ & 88.439 .353 .590 & 4,728 \\
\hline CESP4 & CESP & $\mathrm{PN} *$ & 31.148 .968 .950 & 0,255 \\
\hline CPLE3 & COPEL & $\mathrm{ON} *$ & 21.703 .841 .304 & 0,195 \\
\hline CPLE6 & COPEL & PNB* & 100.284 .416 .577 & 1,147 \\
\hline CPSL3 & COPESUL & $\mathrm{ON}$ & 61.707 .013 & 1,182 \\
\hline CPFE3 & CPFL ENERGIA & $\mathrm{ON}$ & 77.417 .169 & 1,168 \\
\hline DASA3 & DASA & $\mathrm{ON}$ & 21.884 .087 & 0,511 \\
\hline ELET3 & ELETROBRAS & $\mathrm{ON} *$ & 97.855 .894 .019 & 2,362 \\
\hline ELET6 & ELETROBRAS & PNB* & 94.222 .442 .885 & 2,288 \\
\hline ELPL4 & ELETROPAULO & $\mathrm{PN} *$ & 7.265 .960 .225 & 0,435 \\
\hline EMBR3 & EMBRAER & $\mathrm{ON}$ & 88.882 .759 & 0,83 \\
\hline EMBR4 & EMBRAER & $\mathrm{PN}$ & 400.191 .026 & 5,009 \\
\hline GOLL4 & GOL & $\mathrm{PN}$ & 50.974 .919 & 1,553 \\
\hline MYPK4 & IOCHP-MAXION & $\mathrm{PN}$ & 13.030 .583 & 0,123 \\
\hline ITAU4 & ITAUBANCO & $\mathrm{PN}$ & 515.014 .740 & 17,264 \\
\hline ITSA4 & ITAUSA & $\mathrm{PN}$ & 1.676 .948 .007 & 7,582 \\
\hline NATU3 & NATURA & ON & 22.221 .580 & 1,25 \\
\hline PRGA4 & PERDIGAO S/A & $\mathrm{PN}$ & 20.068 .567 & 0,836 \\
\hline SUZB5 & SUZANO PAPEL & PNA & 99.736 .825 & 0,759 \\
\hline TBLE3 & TRACTEBEL & $\mathrm{ON}$ & 141.811 .124 & 1,172 \\
\hline UBBR11 & UNIBANCO & UNT & 584.280 .924 & 9,569 \\
\hline VCPA4 & V C P & $\mathrm{PN}$ & 85.820 .619 & 1,392 \\
\hline WEGE4 & WEG & $\mathrm{PN}$ & 216.429 .750 & 0,979 \\
\hline \multicolumn{3}{|c|}{ Quantidade Teórica Total } & 462.563 .660 .111 & 100 \\
\hline \multicolumn{3}{|c|}{ Redutor } & $166.995 .378,96$ & \\
\hline
\end{tabular}

(*) Cotação por lote de mil ações

\footnotetext{
1 No Brasil são comumente utilizados o retorno de títulos públicos federais de certificados de depósitos interbancários ou da poupança, embora persistam, ainda, controvérsias sobre o ativo que deveria ser considerado livre de risco no país.

${ }^{2}$ De fato, somente a partir de 24/03/2005 existiam todas as ações que compõem o ISE atualmente. Como exemplo, a ação América Latina Logística (ALLL11) só começou a ser listada em 24/03/05.
} 